\title{
Construções Discursivas acerca do Usuário do Programa Saúde da Família (PSF)
}

Discoursive Constructions Regarding Health Care

Consumers of the Family Health Program (FHP)

Construcciones Discursivas acerca del Usuario del Programa Salud de la Familia (PSF)

Martha Traverso-Yépez,

Ana Silvia de Morais \& Mariana Cela

Universidade Federal do Rio Grande do Norte
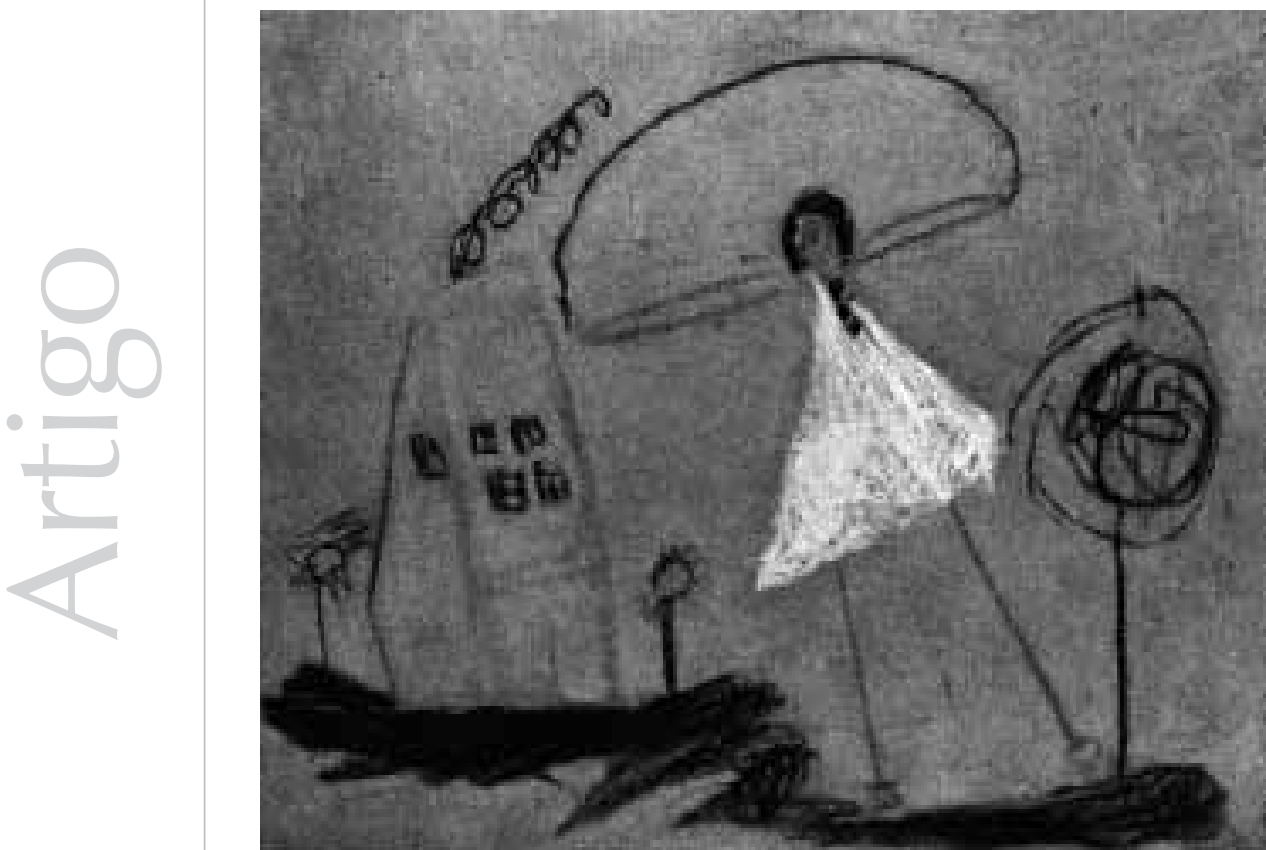
Resumo: O Programa Saúde da Família (PSF), porta de entrada do Sistema Único de Saúde (SUS), tem como um de seus pilares a formação de vínculos de compromisso e de co-responsabilidade com o usuário, visando ao controle social do serviço. O presente artigo objetivou aprofundar as formas como esse usuário é posicionado pelos profissionais das equipes de saúde do PSF, nos textos das entrevistas e nos grupos focais desenvolvidos no processo da pesquisa. Adotou-se para a análise a perspectiva discursiva, que se sustenta no reconhecimento da força constitutiva dos discursos e no seu papel no ordenamento da vida social e na provisão de posicionamentos de sujeitos. As construções discursivas foram organizadas pela temática evocada, e identificaram cinco tipos de discursos: 1) necessidades e problemas dos usuários; 2) desconfianças dos usuários em relação ao PSF; 3) insatisfações dos usuários com o serviço; 4) relações de conflito entre profissionais e Conselho Gestor e 5) falas de co-responsabilidade. A análise discursiva evidencia as dificuldades de trabalhadores e gestores em construir relações horizontais e de diálogo com os usuários, em função das relações de poder vigentes no Sistema Único de Saúde (SUS), perpassado por grandes desigualdades sociais.

Palavras-chave: Construções discursivas. Programa Saúde da Família. Usuários do PSF. Análise discursiva.

Abstract: The Family Health Program is the main strategy of primary health care in the Universal Health System in Brazil and its core tenets are the participation and the social control of the program by the health care users. Therefore, the aim of this work was the analysis of the different ways consumers were described and positioned in the interviews and focal groups developed with professionals and staff managers. The discourse analysis perspective adopted for this task relies on the recognition of the constituting force of discourses and their role in the ordering of social life and the provision of the subjects' positions. The selected discursive constructions were organized by the subject, and identified five type of discourses: 1) the users' needs and problems; 2) the users' mistrust in regard to the FHP; 3 ) the users' dissatisfaction with the service; 4) the conflictive relations between professionals and the Community Council members and 5) co-responsibility discourses. The discursive analysis shows the difficulties professionals and staff management have to construct horizontal and dialogical relationships with the users, due to the power relations at the Universal Health System (SUS), permeated by strong social inequality.

Keywords: Discursive constructions. Family Health Program. Health care consumers. Discourse analysis.

Resumen: El Programa Salud de la Familia (PSF), puerta de entrada del Sistema Único de Salud (SUS), tiene como uno de sus pilares la formación de vínculos de compromiso y de co-responsabilidad con el usuario, pretendiendo el control social del servicio. El presente artículo tuvo como objetivo profundizar las formas como ese usuario es posicionado por los profesionales de los equipos de salud del PSF, en los textos de las entrevistas y en los grupos focales desarrollados en el proceso de la pesquisa. Se adoptó para el análisis la perspectiva discursiva, que se sostiene en el reconocimiento de la fuerza constitutiva de los discursos y en su papel en el ordenamiento de la vida social y en la provisión de posicionamientos de sujetos. Las construcciones discursivas fueron organizadas por la temática evocada, e identificaron cinco tipos de discursos: 1) necesidades y problemas de los usuarios; 2) desconfianzas de los usuarios con relación al PSF; 3 ) insatisfacciones de los usuarios con el servicio; 4) relaciones de conflicto entre profesionales y Consejo Gestor y 5) elocuciones de co-responsabilidad. El análisis discursivo evidencia las dificultades de trabajadores y gestores en construir relaciones horizontales y de diálogo con los usuarios, en función de las relaciones de poder vigentes en el Sistema Único de Salud (SUS), recorrido por grandes desigualdades sociales.

Palabras clave: Construcciones discursivas. Programa Salude de la Familia. Usuarios del PSF. Análisis discursivo.

O presente trabalho faz parte de uma pesquisa desenvolvida no Programa Saúde da Família (PSF) em um bairro de Natal. O delineamento metodológico estruturouse a partir da proposta da etnografia institucional, objetivando estudar os processos organizacionais e institucionais do programa. Considera-se que as relações sociais estão mediadas por textos ou práticas discursivas, organizadas funcionalmente em campos específicos de atividade e que se expressam na dinâmica institucional, reforçando ou mudando o que está instituído.

O estudo aqui apresentado objetivou desenvolver uma sistematização e análise dos discursos de profissionais e de gestores do PSF acerca das diferentes imagens dos usuários do sistema, a partir do corpus de dados construído no processo da pesquisa 
já citada. A perspectiva discursiva adotada sustenta-se no reconhecimento da força constitutiva dos discursos e do seu papel no ordenamento da vida social e na provisão de posicionamentos de sujeitos.

Assim, quando alguém assume um posicionamento, revela, na sua estrutura de valores e no uso que faz de determinado repertório, tanto um conjunto conceitual/ interpretativo quanto uma visão da pessoa de quem se está falando (Davies \& Harré, 1990). Da mesma forma, os enunciados não apenas descrevem as diferentes realidades dos atores sociais envolvidos mas também contribuem para moldá-las, veiculando o conteúdo proposicional e a indicação do ato que desejam efetuar (Spink \& Medrado, 1999). Portanto, ao falarem a respeito dos usuários, os profissionais também evidenciam o tipo de relação que estabelecem com eles. Ao mesmo tempo, essas práticas discursivas influenciam de alguma forma as práticas e as possibilidades de ação dos usuários, que, por sua vez, afetam os profissionais, visto que todo encontro pressupõe uma dinâmica de intersubjetivação (mútua afetação) entre as pessoas que dele fazem parte.

Considerando que o sucesso do Programa se baseia na participação e no envolvimento da população com os trabalhadores e suas práticas, torna-se necessária a reflexão sobre as sutilezas envolvidas nas relações interpessoais que perpassam essa prática de atenção primária à saúde.

O PSF foi criado pelo Ministério da Saúde em 1994, inspirado em experiências de países como Cuba, Inglaterra e Canadá, com o principal propósito de reorganizar, em novas bases, a atenção primária à saúde. No momento, o Programa está presente em quase 5.000 Municípios, e atinge aproximadamente $45 \%$ da população no Brasil, tendo maior presença nas áreas urbanas e rurais de baixa renda das Regiões Norte e Nordeste (Ministério da Saúde, 2005).
Idealmente, a Estratégia Saúde da Família (ESF) prioriza as ações de prevenção, promoção e recuperação da saúde das pessoas, de forma integral e contínua, por meio de atendimentos prestados na unidade básica de saúde, no domicílio ou através da mobilização da comunidade. Fundamentando-se nos princípios da atenção básica no Brasil, quais sejam: integralidade, qualidade, eqüidade e participação social, os profissionais (médicos, enfermeiros, auxiliares de enfermagem, odontólogos, assistentes de odontologia e agentes comunitários de saúde) são organizados em equipes, que propõem práticas gerenciais e sanitárias, democráticas e participativas dirigidas às populações de territórios delimitados. A atuação das equipes caracteriza-se como porta de entrada de um sistema hierarquizado e regionalizado de saúde e propõe-se, ainda, intervir sobre os fatores de risco aos quais a comunidade está exposta, prestando assistência integral, permanente e de qualidade e realizando atividades de educação e promoção da saúde (Ministério da Saúde, 2005).

Contudo, estudos sobre o PSF apontam a ausência da população como protagonista nos cuidados da sua saúde (Crevelim, 2005; Franco \& Merhy, 2004; Matumoto, 2003). O próprio processo desta pesquisa mostra que, embora o PSF se sustente na participação e no controle social, formas verticais de relacionamento continuam deixando o usuário passivo na dinâmica de cuidar da sua saúde, o que tende a excluí-lo da esfera das decisões que the dizem respeito (TraversoYepéz, Bernardino, \& Gomes, 2007; TraversoYepéz, no prelo). O usuário fica, portanto, sem autonomia e sem voz para cumprir o que dele se espera, constituindo-se essa situação de desigualdade em mais um obstáculo para a oferta de um serviço de qualidade, daí a importância de se investigar as práticas discursivas dos profissionais e gestores do PSF, buscando compreender e refletir sobre as múltiplas imagens que constroem do usuário 
do serviço e o tipo de relação/interação que os discursos viabilizam.

\section{Método}

Na dinâmica das relações de poder, através da linguagem se expressa o que pode ser falado, por quem, onde e quando, 0 que delimita os posicionamentos dos sujeitos envolvidos e tende a privilegiar as versões de realidade que legitimam as práticas sociais instituídas

(Parker, 1992).

O material analisado provém de um corpus de dados construído na dinâmica da pesquisa realizada no PSF, nas três unidades de saúde de um bairro de periferia em Natal (TraversoYépez et al., 2007; Traverso-Yépez, no prelo). As estratégias metodológicas da pesquisa foram fundamentadas na perspectiva da etnografia-institucional (Campbell \& Gregor, 2002; Devault \& McCoy, 2002; Smith, 2005), que, segundo essa última autora, é um método de exploração das relações normalizadas que fazem parte do cotidiano de uma instituição; o foco do estudo, portanto, não são as pessoas, mas as atividades e as práticas dos atores sociais e os tipos de relações envolvidas que se cristalizam em "textos".

Na perspectiva da etnografia institucional, os textos são as falas, ações ou práticas sociais corriqueiras que acontecem no cotidiano dos serviços públicos de saúde, geralmente de forma não-reflexiva. Por meio da sua "leitura", é possível apreender o universo simbólico que perpassa tais práticas e as relações institucionais, que abrigam relações de poder que se expressam através desses diferentes tipos de textos.

Dessa forma, para os efeitos do presente estudo, foram usados, prioritariamente, os textos das entrevistas e dos grupos focais desenvolvidos com os profissionais do PSF bem como com gestores da Secretária de Saúde. Adotou-se para análise a perspectiva discursiva desenvolvida por psicólogos sociais britânicos sob a influência das idéias pósestruturalistas de Michel Foucault. (Parker, 1996; Willig, 2001). Essa versão discursiva, denominada pelos autores perspectiva discursiva foucaultiana, considera que os discursos constroem realidades psicológicas e sociais a partir do momento em que apontam as formas como as pessoas pensam ou sentem (subjetividade), o que fazem (práticas) e as condições materiais em que as experiências são processadas. Assim, a perspectiva relaciona os discursos às práticas institucionais, considerando que organizam, administram e regulam a vida social. $\mathrm{Na}$ dinâmica das relações de poder, através da linguagem se expressa o que pode ser falado, por quem, onde e quando, o que delimita os posicionamentos dos sujeitos envolvidos e tende a privilegiar as versões de realidade que legitimam as práticas sociais instituídas (Parker, 1992).

No tocante ao processo de formulação e sistematização das construções discursivas, os passos seguidos a partir do corpus de dados foram: 1. Leituras exaustivas de todo o material na procura das construções discursivas relacionadas à temática deste trabalho; 2. Identificação das construções que faziam referência de forma explícita ou implícita aos usuários do serviço, situadas sempre no contexto da fala; 3 . Sistematização e análise de cada construção discursiva a partir dos sentidos que estão sendo evocados; 4. Caracterização das construções discursivas em categorias mais abrangentes de discursos, delineando a variabilidade de aspectos considerados.

Na discussão, busca-se explorar, ainda, a orientação para a ação bem como o tipo de prática que essas construções discursivas e os posicionamentos dos sujeitos nelas contidos viabilizam. Finalmente, no item das considerações finais, assinalam-se os desafios que a pesquisa levanta.

As construções discursivas estudadas

Para efeitos da análise, após a leitura exaustiva do material e a identificação das construções discursivas relacionadas aos usuários do serviço, procedeu-se à sistematização e análise das mesmas a partir dos sentidos que 
eram evocados. Assim, as construções discursivas dos profissionais e gestores da saúde foram agrupadas em cinco categorias ou tipos de discursos: 1) as necessidades e os problemas dos usuários; 2) as desconfianças dos usuários em relação ao PSF; 3) as insatisfações com relação ao PSF; 4) as relações de conflito entre os profissionais e o Conselho Gestor e, 5) as falas de co-responsabilidade. Na Tabela 1, apresentam-se as construções discursivas com a variedade de posicionamentos dos usuários, agrupadas nos cinco tipos de discursos. A seguir, procede-se a uma explicação mais detalhada das mesmas.

Tabela 1. Construções discursivas acerca dos usuários.

1 - Necessidades e problemas dos usuários

1.1 Usuário como alguém em situação de dificuldade social, o que implica demandas difíceis de atender nas práticas de saúde instituídas;

1.2 Usuário como alguém fragilizado, que necessita de acolhimento;

1.3 Usuário como alguém carente de conhecimento.

2. Desconfianças dos usuários em relação ao PSF

2.1 Usuário como alguém de uma cultura diferente, que precisa melhorar seus conhecimentos e hábitos de vida;

2.2 Usuário que se sente vigiado;

2.3 Usuário que precisa de tempo para entender os benefícios do programa.

3. Insatisfações dos usuários em relação ao PSF

3.1 Usuário que demanda urgência em seu atendimento quando está com problemas de saúde;

3.2 Usuário influenciado pelo modelo médico-centrado;

3.3 Usuário que cobra seus direitos;

3.4 Usuário agressivo.

4. Relações de conflito entre profissionais e Conselho Gestor

4.1.Usuários do Conselho Gestor que trabalham mais em favor de interesses próprios do que em prol da comunidade;

4.2 Usuários do Conselho Gestor são considerados ameaça pelos profissionais.

5. Falas de co-responsabilidade

5.1 Satisfação do usuário depende das boas condições de trabalho dos profissionais do PSF;

5.2 Usuário como co-responsável pelo sucesso do PSF.

1. Necessidades e problemas dos usuários

Nessa primeira categoria de discurso, os profissionais e gestores do PSF consideram que a clientela atendida pelo Programa seja formada, em sua maioria, por uma população sacrificada, que sofre com problemas sociais diversos, e que estes acabam repercutindo em suas condições de saúde. Nesse teor, o usuário é posicionado: 1.1. como alguém em situação de dificuldades sociais, o que implica demandas difíceis de atender nas práticas de saúde instituídas; 1.2. como alguém fragilizado que precisa de acolhimento e 1.3. como alguém carente de conhecimento.

1.1 Usuário como alguém em situação de dificuldades sociais, o que implica demandas difíceis de atender nas práticas de saúde instituídas

Os discursos apontam a interdependência entre saúde e condições sociais, admitindo que a resolução de muitas demandas da comunidade está associada à esfera política. Destaca-se 
a ausência dos governos na satisfação de necessidades sociais básicas para grande parte da população atendida, faltando apoio de outras áreas para solucionar conjuntamente as carências estruturais no bairro:

-Eu não vou ter o mesmo resultado se eu chegar numa casa onde tem várias crianças com escabiose... tá certo, o médico vai lá, trata toda aquela escabiose... mas, de repente, aquela criança não tem água potável, não tem saneamento na rua dela, existe um lixão próximo à casa dela... a gente tenta trabalhar em parceria com as outras secretarias, com as outras instituições... como eu digo... saúde não se faz só com um médico, um enfermeiro e um dentista... (Grupo focal com as equipes de uma unidade)

Observam-se, ainda, as dificuldades em concretizar a intersetorialidade, premissa básica do PSF, especialmente pela ausência de uma estrutura organizativa que dê conta dos problemas associados à falta de condições adequadas de vida de significativa porcentagem da população.

1.2 Usuário como alguém fragilizado, que necessita de acolhimento

Como já ressaltado antes, por representarem o elo entre o usuário e o poder público, as unidades do PSF se deparam diariamente com as insatisfações advindas da precariedade dos serviços sociais voltados para a comunidade. Embora em algumas das construções discursivas se observe uma sensação de impotência diante da complexidade dessas questões, alguns trabalhadores comentam a necessidade de acolher e ajudar essa população fragilizada.

Nesses discursos, também está presente a idéia de que os conflitos sociais e culturais que os usuários enfrentam podem se refletir em questões emocionais, que os levam à unidade de saúde em busca de escuta, acolhimento e oportunidade de compartilhar experiências:
...As portas são abertas pra o pobre, pra o rico, pra o preto, pra o branco, qualquer pessoa. Não podemos proibir. E segundo: eu não sei se você percebe, mas, para algumas pessoas, a unidade de saúde é um lazer. É onde às vezes a dona de casa tá aperreada com o marido, brigou, chega lá, se senta e uma pessoa começa a conversar, escuta uma piada de um, escuta uma conversa de outro, né? Ela sai dali relaxada. Não veio nem pra uma consulta. Ela só veio pra que alguém ouvisse. (Entrevista com gestor/a)

Há o reconhecimento, entre alguns dos profissionais, do potencial terapêutico das relações interpessoais que são viabilizadas nas unidades. Essa consideração da relevância dessas relações poderia ajudar as equipes a transcenderem a visão reducionista de saúde. Na prática, no entanto, pelas limitações de tempo e especialmente pela hegemonia do modelo biomédico vigente, o que predomina são atendimentos clínicos padronizados e impessoais.

\subsection{Usuário como alguém carente de conhecimentos}

Nos discursos de alguns profissionais, há a idéia de que um dos entraves na relação com os usuários é o limitado conhecimento que a população possui acerca do Programa Saúde da Família:

\footnotetext{
...a comunidade, ela ainda não está a par do que é realmente o PSF. Ele (usuário) quer um serviço de saúde. Ele não tem na cabeça dele o que é o PSF e o que é posto de saúde. Nós é que tentamos dar a parte curativa, mas não perder de vista a filosofia do programa, o que o programa prega....

...O erro foi isso, a população não foi elucidada sobre o que era o PSF. Se tivesse acontecido isso, os problemas seriam muito menores. (Grupo focal com as equipes de uma unidade)
}

Observa-se que os profissionais insistem na perspectiva da prevenção e promoção da saúde como característica do Programa, 
enquanto os usuários insistem na procura de atendimento assistencial para seus problemas imediatos de saúde. Deve-se considerar que, devido as suas condições de vida, as pessoas adoecem com freqüência, o que obriga os profissionais a se centrarem na assistência médica primária e/ou na atenção primária seletiva.

Segundo os participantes, as ações de prevenção e promoção da saúde limitam-se aos programas especiais (diabéticos, hipertensos, aleitamento, vacinação, etc.). Da mesma forma, pela falta de tempo e/ou formação, as intervenções tendem a ser rápidas e centradas na doença, desconsiderando a relevância do diálogo com o usuário e deixando também de lado o que acontece com as outras dimensões do processo saúde-doença, tais como os aspectos sociais e culturais (Vasconcelos, 1999).

Em muitos textos também, de forma implícita ou explícita, destaca-se a falta de conhecimentos básicos do usuário, o que coloca em risco sua saúde:

Hoje eu recebi um paciente que precisaria de 60 seringas de insulina. Ele recebeu 10. Uma seringa é mais de 1 real, ele jamais vai ter dinheiro pra comprar essas $50 \ldots$ muitos reaproveitam... é um perigo... é um risco intermitente, principalmente porque a gente tá vendo que eles não têm a noção de higiene... (Grupo focal com as equipes de uma unidade)

Outros discursos enfatizam ainda a pouca credibilidade no potencial do usuário, o que inviabilizaria as ações de co-responsabilidade, conforme este depoimento: "Como pode haver co-responsabilidade se a comunidade não tem condições de acatar o que é explicado?" (Depoimento registrado em oficina de planejamento em uma das unidades).

Nota-se que, embora o depoimento faça referência às condições materiais, o termo "acatar" evidencia o caráter autoritário do discurso, apresentando o usuário como elemento passivo em uma relação desigual.

2. Desconfianças dos usuários em relação ao PSF

No segundo tipo de discursos, aparecem as dificuldades que alguns profissionais encontram em lidar com uma população que se mostra desconfiada, resistente a mudanças e que possui hábitos considerados "diferentes". De alguma forma, em todas as construções, os usuários são posicionados como um "outro" que precisa se adaptar à dinâmica do PSF. Nessa temática, o usuário é posicionado como: 2.1. alguém de uma cultura diferente, que precisa melhorar seus conhecimentos e hábitos de vida; 2.2. alguém que se sente vigiado; 2.3. alguém que precisa de tempo para entender os benefícios do programa.

\subsection{Usuário como alguém de uma cultura} diferente, que precisa melhorar seus conhecimentos e hábitos de vida

As diferenças culturais são centrais nesse tipo de discurso, no qual se observa a dificuldade dos profissionais em desenvolver relações dialógicas acerca dessas diferenças. Tende-se a manter concepções hierarquizadas a respeito dos ditames da cultura biomédica e a ver pejorativamente os costumes vigentes entre os usuários, insistindo na necessidade de impor os primeiros à população. Os discursos dos profissionais em um grupo focal, em umas das unidades, ilustram melhor essa problemática:

... Tava falando a questão de ferver a água ou a hipótese de comprar um filtro. O homem disse que tinha ganhado uma jarra, que ia pegar um pano de prato limpo e ia coar a água, que nem no interior. Eu perguntei... qual é o tratamento que ele tá fazendo na água que tá tomando. Ele disse que no 
interior... ele não fazia assim? Entendeu? (...) E ele acha que coar a água que vem da CAERN num pano de prato ia ser um tratamento adequado.

...Educação em saúde é uma coisa que a gente tem que tá assim, todos os dias, né, falando, falando, falando e sabendo que a resposta nem todo tempo é o que a gente espera. É a resposta que o rapaz deu a X: "eu vim do interior, e lá minha água era coada, eu nunca tive nada". Então eu lembro, agora eu lembro que minha casa lá no interior era uns pote, e a água vinha na carroça, e o tratamento que era dado a ela era coada num pano de prato. Eu vivi na minha infância isso, né? E isso me recordou agora. ...Tem coisas que a gente também não pode simplesmente achar que as pessoas vão ter uma mudança radical. É o que tá colocando aqui, a questão do processo lento. (Grupo focal com as equipes de uma unidade)

Ao mesmo tempo em que os falantes desses discursos posicionam o usuário em uma cultura diferente, também trazem à tona o fato de que as mudanças culturais são um processo complexo e demorado. O depoimento do primeiro profissional trouxe experiências da própria vivência, já esquecidas, a outro profissional, que, no segundo fragmento discursivo, faz o esforço de se colocar no lugar do usuário e refletir acerca da complexidade da questão.

Em outro grupo focal, alguns profissionais se lamentam de que há resistência entre algumas mães para aceitar os cuidados da saúde propostos pelos profissionais, como o aleitamento materno e o uso do soro caseiro, entre outros:

Pra vocês verem... o que eu falei que é muito difícil a gente mudar a cultura das pessoas, né... a gente fala disso desde antes de ela engravidar... em aleitamento materno, que salva vidas, né. Mas quando ela tem menino, que a vizinha chega e diz: "menina, esse leite é fraco, eu criei oito meninos... nunca dei isso, e tá tudo vivo". Quer dizer, é um trabalho difícil, porque as pessoas estão com aquilo já na mente.
Quantas pessoas a gente já disse: soro caseiro é uma coisa importante quando tem a diarréia, e que ninguém acredita!? Quer dizer, essa é a parte do trabalho da gente mais difícil, é mudar os hábitos das pessoas. Isso é mudança. E isso não é fácil, não é fácil pra nós também. (Grupo focal com as equipes de uma unidade)

Por um lado, no caso do aleitamento, as questões contextuais são novamente esquecidas, como o fato de, por razões de trabalho e/ou por problemas de falta do leite, algumas mães não se sentirem confiantes em amamentar. Por outro lado, seria preciso lembrar que, no Brasil, décadas atrás, o sistema médico prescrevia o leite artificial e, muitas vezes, ainda na maternidade, administravam injeções nas mães para inibir a produção de leite, ao tempo em que as campanhas de televisão faziam apologia ao leite em pó. Existe, ainda, o peso ideológico da preferência pelos produtos de fabricação industrial, incutido pelo modelo biomédico e pela dinâmica consumista existente também no campo da saúde.

\subsection{Usuário que se sente vigiado}

Alguns discursos enfatizam que certos usuários se sentem controlados demais pelo sistema de cadastramento do PSF, seja para a distribuição de medicamentos, seja para o acompanhamento de vacinas ou o controle do fluxo de moradores no bairro.

Por que... que todo mês hipertenso tem que ser cadastrado, gente!? Eles já tão que não mai agüentam. Eles estão se sentindo marginalizados com isso. Uma, na semana passada, olhou pra gente e disse: "minha filha, será que eu tou roubando alguma coisa? Porque todo mês quando eu chego aqui pra receber, eu tenho que me cadastrar". Então, tá na hora da gente rever isso. (Grupo focal com as equipes de uma unidade) 
Observa-se que as medidas burocráticas do sistema causam constrangimentos tanto para os usuários quanto para os trabalhadores, especialmente para os agentes de saúde, que têm mais contato com a população. Os profissionais apresentam o usuário como alguém que tem a percepção de tal aspecto, e demonstram a vontade de se colocar no seu lugar e de problematizar a questão.

\subsection{Usuário que precisa de tempo para} entender os benefícios do Programa

Alguns depoimentos destacam os benefícios do Programa, deixando implícita a idéia de que, se os usuários não estão satisfeitos com sua dinâmica, isso ocorreria apenas por não terem percebido ainda o quanto podem ser beneficiados por ela. Discursos como esses parecem minimizar as insatisfações da comunidade, como se elas fossem produtos de uma percepção distorcida sobre os serviços oferecidos:

Você vê um usuário assustado. Quando esse usuário... começa a perceber, é que hoje em dia ele pode contar com um médico, que ele pode contar com uma equipe, que ele pode dizer que fulano de tal é o médico da minha equipe, que a enfermeira fulana de tal é a enfermeira da minha equipe... Então, quando ele começa a perceber isso, aí você já começa a ver, lógico, um usuário mais satisfeito, mais, é, aceitou o PSF entendendo um pouco, porque também não é da noite pra o dia que ele vai entender todo esse processo. (Grupo focal com gestores)

Percebe-se, no discurso, o poder simbólico das práticas de saúde, consideradas um fator de satisfação do usuário que finalmente consegue aproximar-se delas. É possível caracterizar discursos como esses de ideológicos, visto que mantêm, mesmo que involuntariamente, uma visão idealizada dos profissionais da saúde e de seu poder simbólico (Thompson, 1995). Por outro lado, são evidentes também as relações de desigualdade entre sistema de saúde e usuário.

No contato com os usuários, observouse que o simples fato de contar com um médico e uma equipe não os torna satisfeitos. Geralmente, o que importa é a relação que esses profissionais estabelecem com os usuários. Como fora expresso em um grupo focal de usuários: "Eu agradeço por estar na equipe $X$... a médica é muito preocupada e me escuta".

\section{Insatisfações dos usuários com o serviço}

Os freqüentes desencontros entre a proposta do Programa e as demandas dos usuários estão presentes também em algumas construções discursivas. Geralmente, esse tipo de discurso faz referência a um usuário que reivindica seus direitos e expressa suas demandas até de forma agressiva, apontando: 3.1. usuário que demanda urgência em ser atendido quando está com problemas de saúde; 3.2. usuário influenciado pelo modelo médico-centrado; 3.3. usuário que reivindica seus direitos; 3.4 . usuário agressivo.

3.1 Usuário que demanda urgência em ser atendido quando está com problemas de saúde

Esses textos enfatizam aquilo que os profissionais consideram pressão exagerada por parte dos usuários em terem suas demandas mais urgentes atendidas:

...Tem que atender até a hora que eles querem... Aqui tem gente que, no posto fechado, chega e quer que a diretora abra pra ele ser atendido. Mas também a gente tem o direito de beber a água da gente, deitar, ou lanchar, ou descansar, ir pra casa almoçar, voltar... já que é de 7:30 às 11:30, e de 1:30 às 5:30. ...minha filha, é hora da gente almoçar. São insistentes, persistentes, sem limite! Porque tem que atender de qualquer maneira... (Grupo focal com as equipes de uma unidade) 
Então a gente briga constantemente com a cultura de que você não precisa estar de duas horas da manhã numa fila pra pegar uma ficha, de que o médico pode ir a sua casa quando você não... não pode se locomover até a unidade de saúde, quando um agente de saúde chega na sua casa e ensina como você deve tratar sua água, como está o peso do seu filho, como você deve manter a higiene. (Grupo focal com gestores)

Esses objetos discursivos enfatizam, ainda, a falta de compreensão de alguns usuários em aceitar o que é oferecido pelo Programa, o que resulta em uma parte da população ainda atrelada aos moldes do sistema de atendimento anterior. Contudo, como destacado nos grupos focais, falta o necessário diálogo com a comunidade acerca da proposta do PSF. Os discursos mostram que o embate com a cultura do usuário parece apenas reforçar posições de poder, não promovendo as relações horizontais que são apregoadas pela Estratégia Saúde da Família.

\subsection{Usuário influenciado pelo modelo médico-centrado}

Os discursos revelam que os usuários reproduzem a visão do modelo biomédico e da perspectiva curativa de saúde em suas atitudes e práticas:

...Na realidade, o que a população quer é a parte curativa. Mas a gente tá trabalhando... para fazer a população entender que, se a gente não fizer a parte preventiva, a gente vai ficar aqui 10 anos, não é, numa sala, atendendo, atendendo... passar um remédio pra verme, passa um remédio pra hipertenso.... Eles acham que o médico e o enfermeiro, eles estão no posto de saúde para fazer a parte curativa... é fruto de toda uma população que ficou jogada no ostracismo sem nunca ter tido nenhum tipo de assistência, só conhece o modelo convencional, e acha que o que está, que o que tem ali dentro é modelo, é pra ser repetido o modelo convencional. (Grupo focal com as equipes de uma unidade)
Assim, por meio dos discursos dos profissionais, percebe-se que os usuários mostram certo abuso no uso indiscriminado de medicamentos, desvalorização de profissionais da área de saúde que não são médicos e preferência por especialistas em detrimento dos profissionais generalistas: "...Mas usuário chega na minha sala e diz: 'eu quero ir pro médico tal, eu quero ir pra especialidade tal', então isso quem determina não é o usuário, né? Quem determina é uma consulta, não é verdade? (Grupo focal com gestores)

Pra eu convencer essa moça que era o mesmo remédio, foi difícil. Aliás, eu nem convenci. Como tem um médico que mora vizinho à gente, ela conversou com ele e acreditou porque ele disse. E eu até disse a ele: "eu disse tantas vezes e não acreditou em mim, precisou falar com um doutor!" Quer dizer, aconteceu lá e acontece aqui.... A força do médico é maior que todo mundo, por mais que você não queira. (Grupo focal com as equipes de uma unidade)

Outro aspecto desse modelo médicocentrado, como já discutido, é a dinâmica consumista no campo da saúde. Ela leva a crer que qualquer medicamento comprado na farmácia será melhor do que produtos naturais, como é o caso do soro comercializado:

Mas as pessoas não têm credibilidade pelo soro caseiro, elas têm mais credibilidade pelo saquinho que elas pegam no posto de saúde, a embalagenzinha, entendeu? (...) Mas sabe o que é? A gente faz e a gente orienta, mas elas querem o soro do pacote, querem! Tem gente que chega e diz: "Ai, minha despensa de remédio está seca". Sua despensa deve estar seca! Não é pra tá cheia de remédio, não você tá dando remédio errado aos seus filhos e depois tá aí com problema pior. (Grupo focal com as equipes de uma unidade).

A dinâmica da medicalização está muito enraizada na população. Dessa forma, em um grupo focal com usuários, quando questionados sobre o que era saúde para eles, grande parte do tempo comentaram 
que saúde era ter "um atendimento médico... ter os medicamentos de que precisamos", lamentando-se de que sofriam muito "por ter que depender da saúde pública ao não ter condições de pagar um plano de saúde". Contudo, não faltaram usuários que disseram preferir remédios caseiros a enfrentar longa espera nas unidades.

\subsection{Usuário que cobra seus direitos}

Apesar de a proposta do PSF ter como um de seus pressupostos o controle social, algumas falas evidenciam o incômodo dos profissionais com os usuários que reivindicam de forma enérgica o direito de serem atendidos ou de receberem medicamentos:

Eu acho que a primeira família que foi para o dentista foi uma... (família) minha. Foi a que mais cobrava, e eu coloquei pra ser atendida aquelas pessoas que realmente são as mais ignorantes, mais agressivas, aquelas pessoas que mais cobram. (Grupo focal com as equipes de uma unidade)

Passou na televisão a reportagem sobre isso aqui, que o rapaz da drogaria mesmo falou, "pode cobrar na unidade de saúde que é direito, é direito ter o medicamento". Só que eu assisti, e disse: "como é que pode um cara desse dizer um negócio desse na televisão". (Grupo focal com as equipes de uma unidade)

Observa-se que, no primeiro discurso, as pessoas que exigem são consideradas "ignorantes e agressivas", o que aponta a atitude de passividade que muitos profissionais esperam da maioria dos usuários do programa. No segundo, o discurso do profissional critica a veiculação dos direitos da comunidade na televisão, já que isso poderia repercutir em aumento de demandas e reclamações nas unidades do PSF. Indiretamente, a fala pretende fixar o usuário em um lugar de desinformação, restringindo-lhe as possibilidades de atuar como cidadão. Assim, são comuns textos que deslegitimam os discursos da população menos favorecida que, no momento em que reclama por seus direitos, passa a ser vista como grosseira e até mesmo agressiva, como veremos a seguir.

\subsection{Usuário agressivo}

Esse tipo de discurso enfatiza a forma agressiva como alguns usuários se apresentam em certos momentos. A funcionalidade dessas falas dos profissionais parece ser a de se apresentarem como pessoas que sofrem situações até de perigo no desempenho do seu trabalho:

\footnotetext{
Tem gente, tem paciente que chega e manda, a gente vai conversar e não entende, querem bater na gente. E já aconteceu comigo! (...) Depois vieram me dizer, com três dias, que ela tinha furado o marido dela. Se ela fez com o marido dela, ia fazer o quê comigo? (Grupo focal com as equipes de uma unidade)

E a comunidade também é acomodada..., porque é mais fácil ele bater de frente com a gente do que bater de frente lá com o poder público, num é? E eles descontam, extravasam a raiva deles todinha com a gente aqui, e a gente também não resolve nada... não é com a gente que eles vão ter que brigar para conseguir as coisas, que aqui a gente também está de mãos atadas. (Grupo focal com as equipes de uma unidade).
}

Alguns discursos chegam até mesmo a buscar explicações e a dar razão a esse usuário, enfatizando os múltiplos problemas que ele sofre e que o levam "a descontar na gente", apesar dos esforços que muitos profissionais dizem fazer para não virar "saco de pancada" da comunidade.

4. Relações de conflito entre profissionais e Conselho Gestor

Outro ponto de tensão entre profissionais e usuários é o exercício do controle social (apregoado pelo SUS) por meio do Conselho Gestor. Nessas construções discursivas, os 
profissionais destacam: 4.1. usuários do Conselho Gestor que trabalham mais em favor de interesses próprios do que em prol da comunidade; 4.2. usuários do Conselho Gestor são considerados ameaça pelos profissionais.

4.1 Usuários do Conselho Gestor que trabalham mais em favor de interesses próprios do que em prol da comunidade

Nesses discursos, insiste-se que falta formação entre os usuários-conselheiros para desempenhar esse papel, sendo criticadas especialmente a falta de inserção dessas lideranças na comunidade e a gestão personalista:

...E você vê conselheiro que não entende direito qual o papel dele, e acha que é estar fiscalizando, cobrando..., e não é... Mas você vê que... eu já vi conselheiro que o centro da reunião é ele. Se você vai discutir, é ele, né? Então ele tá ali se representando, mesmo, não tem uma inserção na comunidade, mesmo. Muitas vezes, é melhor você chamar diretamente a comunidade. (Grupo focal com as equipes de uma unidade)

Embora seja certo que os conselheiros tendam a ser aquelas pessoas que têm mais experiência e habilidade em lidar com os problemas da comunidade em função de sua participação nas estratégias da politicagem local, isso nem sempre é assim. Contudo, essa imagem é simplesmente generalizada e vilipendiada, sem que se proponha alguma alternativa destinada a facilitar o aparecimento de outras formas de lideranças, mais democráticas e participativas.

4.2 Usuários do Conselho Gestor são considerados ameaça pelos profissionais

As cobranças dos usuários-conselheiros chegam a causar incômodo em alguns dos profissionais, que se sentem "fiscalizados", admitindo a "resistência" que se tem a esse órgão:

Existe certa resistência em função disso, porque o que que poderia fazer? Não, então vamos chamar o Conselho Gestor para se responsabilizar por isso aqui? Né? Mas aí entra a dificuldade muitas vezes por isso, "ah, eles estão aqui para olhar o que a gente tá fazendo". Então assim, acho que é falta de prática, mesmo, de compreensão.

(Grupo focal com gestores)

Como destacado antes, a maior reclamação por parte dos profissionais é a de que os conselheiros costumam agir em benefício próprio. Entretanto, alguns gestores consideraram que os profissionais não apóiam o Conselho, por não compreenderem seu papel ou por se sentirem fiscalizados por ele. Além disso, sentem-se ameaçados nas práticas institucionais que negligenciam os cuidados a favor de formas de intervenção de qualidade.

\section{Falas de co-responsabilidade}

Na direção contrária das construções discursivas acima elucidadas, aparecem também depoimentos de profissionais e gestores que destacam a idéia de uma interdependência entre o envolvimento do usuário, o envolvimento dos profissionais e o sucesso do Programa, demonstrando o reconhecimento de que as práticas de saúde devam ser construídas de forma coletiva.

5.1 Satisfação do usuário depende das boas condições de trabalho dos profissionais do PSF

A mútua influência entre a satisfação dos trabalhadores e a da comunidade atendida é explicitada nos discursos abaixo. Entretanto, o índice de queixas que os profissionais trazem com relação à precariedade do serviço e às condições de trabalho deficitárias, por um lado, e, por outro, às frustrações decorrentes do baixo grau de resolutividade 
dos problemas com que os profissionais lidam geram um clima de desinteresse e baixa motivação. Se a isso se soma a falta de treinamento e/ou a disposição para lidar com a complexidade dos problemas sociais, o resultado é um trabalhador cuja principal motivação tende a ser o retorno econômico:"...Quando você tem uma boa satisfação do funcionário, você vê isso no atendimento com o usuário, tá certo? Você vê essa resposta com o usuário" (Entrevista com gestor/a).

...Nós estamos com uma sobrecarga de trabalho, e às vezes a gente não pode, né, mesmo, a gente quase não se comunica, e isso também faz com que a gente transfira pro próprio paciente. Mesmo sem querer, mas o paciente vê na nossa testa, no nosso semblante. (Grupo focal com as equipes de uma unidade)

Os problemas do cotidiano, tanto pessoais como institucionais, terminam por incidir nas práticas desses profissionais, que tendem a atuar mecanicamente, desconsiderando as necessidades da população assistida.

\subsection{Usuário como co-responsável pelo sucesso do PSF}

Admite-se, nessas falas, que o usuário pode contribuir para o sucesso das práticas em saúde, o que pressupõe um bom relacionamento entre equipes e usuários:

Então eu acho que essa questão do bom relacionamento, ela é, ela tem que ser vista dentro do ponto de vista do bom relacionamento entre os pares, entre o trabalhador e a população. Se você não respeita a população, você não tem o relacionamento eficaz... (Grupo focal com as equipes de uma unidade)

“O usuário tá lá na unidade, e ele tá vendo no dia a dia o que pode ser melhorado, então isso é fundamental, a presença do usuário nesse conselho gestor" (Entrevista com gestor/a).
Ciente de que as unidades são vistas como "espaço de resolução de problemas", alguns profissionais destacam a necessidade de se estabelecer uma comunicação compreensiva e dialógica com o usuário. Entretanto, enfatiza-se que, para isso, seria necessário melhorar os relacionamentos interpessoais nas próprias equipes, o que ainda deixa a desejar. Como destacado por Peduzzi (2001), o trabalho em equipe deveria ter como base a prática comunicativa, pois esta possibilita construir um projeto assistencial comum, adequado às necessidades dos usuários, e não apenas reiterar o projeto institucional.

\section{Discussão}

No presente trabalho, tem-se objetivado sistematizar as construções discursivas que falam a respeito do usuário do serviço na dinâmica das relações sociais instituídas no Programa Saúde da Família (PSF). Dos cinco tipos de discursos: 1) necessidades e problemas dos usuários; 2 ) desconfianças dos usuários em relação ao PSF; 3) insatisfações dos usuários com o serviço; 4) relações de conflito entre profissionais e Conselho Gestor e 5) falas de co-responsabilidade; observa-se que os quatro primeiros apontam claramente formas hierarquizadas de relacionamento entre profissionais e usuários. Apenas no último tipo de discurso são expressas considerações acerca da relevância das relações mais horizontais e de preocupação pelas interdependências existentes em todo fenômeno social.

De qualquer forma, os discursos são ilustrativos da variedade de posicionamentos e perspectivas que podem estar presentes nas relações profissionais-usuários do serviço. Nota-se, na maioria desses discursos, a marca das relações desiguais historicamente sustentadas em nossa sociedade, que expressam o significativo distanciamento entre o profissional ou o gestor e o usuário do serviço, geralmente pertencente a outra 
classe social e que, por isso, tende a ser colocado em situação de desvantagem e de submissão.

Em oficinas de planejamento, nos grupos focais, em conversas informais e nas respostas dos questionários aplicados no decorrer da pesquisa, percebeu-se que os problemas apontados, de forma geral, giravam sempre em torno das condições precárias de vida da população. Assim, profissionais e gestores trazem à tona situações de desnutrição, falta de higiene e saneamento, violência, trabalho infantil, baixo grau de escolaridade, falta de espaços de lazer e falta de ocupações produtivas, bem como as formas de expressão dessas condições negativas na saúde, a citar: prostituição, drogas, dermatoses, bronquites, DST/AIDS, gravidez precoce. Entretanto, geralmente, falta uma reflexão acerca das condições estruturais das iniqüidades instituídas que geram essas situações.

O problema dos discursos que enfatizam as precárias condições de vida, deixando de lado os problemas estruturais de iniqüidades sociais que condenam uma porcentagem significativa da população a essa sobrevivência precária, é que eles tendem, em certos momentos, a responsabilizar os usuários por seus problemas de saúde.

Outra problemática encontrada é o limitado espaço de diálogo que, diante das marcantes diferenças instituídas em função de relações de poder verticais e autoritárias, gera desconfianças e receios que se expressam de formas variadas entre os usuários. As construções discursivas mostram, assim, a necessidade de ir além do controle dos corpos, para uma construção de formas mais democráticas de relacionamento (Gastaldo, 1997).

Às desconfianças, somam-se as diferentes expressões de insatisfação dos usuários, seja porque não compreendem ainda a dinâmica do PSF, seja porque têm incorporado o modelo biomédico, associando a saúde ao consumo de tecnologias médico-farmacêuticas. Observase que a vigência desse modelo tende a desqualificar outros saberes relacionados aos cuidados com a saúde, e, o que é pior, deixa de lado os condicionantes sociais do processo saúde-doença bem como a própria subjetividade do usuário.

As falas dos profissionais acerca das insatisfações e cobranças dos usuários tendem a ser expressões de deslegitimação do potencial do usuário para exercer seus direitos. Vasconcelos (1999) chama a atenção para o fato de que, em uma relação de igualdade, é importante acreditar na legitimidade da fala do interlocutor bem como no desenvolvimento de espaços de escuta e diálogo. Nas relações verticais instituídas, esse tipo de interação não é, de fato, favorecido.

No tocante ao Conselho Gestor, observase que, nos discursos dos profissionais, o controle social tem uma conotação negativa de fiscalização. Prevalece a idéia de que os usuários-conselheiros estão lá apenas em busca de privilégios, e que, através das críticas negativas aos profissionais, geram tensões inaceitáveis nos espaços de trabalho (Crevelim, 2005). Percebe-se que a importância do Conselho Gestor tende a ser esvaziada do seu potencial político devido ao seu eventual mau uso.

Laverack (2005) afirma que a formação de grupos comunitários, como o de Conselhos Gestores, é o primeiro passo em direção a uma ação coletiva. E os profissionais da saúde devem ter um importante papel nesse processo, conectando os usuários entre si e compartilhando com eles seu próprio poder, oferecendo não apenas serviços mas também recursos para esse tipo de ação.

O objetivo desta análise, portanto, não é passar uma imagem negativa dos profissionais 
e/ou gestores nem colocar o usuário como vítima ou agente passivo na dinâmica dos cuidados da saúde. Espera-se, sim, apontar a complexidade da problemática e a grande responsabilidade que recai sobre os ombros dos profissionais e gestores para lidar com as diferenças de poder instituídas.

\section{Considerações finais}

Por meio das construções discursivas analisadas, evidencia-se que, embora os profissionais da saúde não tenham influência sobre a transformação das relações de poder em todos os setores e níveis, o trabalho cotidiano que realizam tem papel fundamental na reprodução e/ou possível modificação na estrutura do sistema de saúde pública (Laverack, 2005). Em primeiro lugar, por influenciarem as políticas e práticas que afetam a saúde no nível nacional ou local, por meio do exercício de seu poder de especialistas em reuniões e trabalhos em comissões técnicas; em segundo, por se envolverem com indivíduos e grupos que, na qualidade de usuários, podem ser estimulados a exercer maior poder sobre suas vidas incluindo a saúde.

Assim, para construir uma prática que dê poder às comunidades de usuários, o campo da saúde pública precisa se livrar das barreiras impostas por sua natureza burocrática e, especialmente, da reprodução não reflexiva das relações de desigualdades vigentes. Da mesma forma, antes que se distribua poder, é preciso que os profissionais tomem ciência e compreendam melhor a fonte de seu próprio poder. Esse processo inclui um ambiente em que se sintam valorizados e em que thes sejam fornecidos recursos, habilidades e reconhecimento do grande desafio que têm pela frente. 


\section{Martha Traverso-Yépez*}

Doutorado em Psicologia Social pelo Universidad Complutense de Madrid (Espanha) e Pós-Doutorado pela Memorial University of Newfoundland, Community Health and Humanities Division (Canadá). Professora titular da Universidade Federal do Rio Grande do Norte (UFRN)

\section{Ana Silvia de Morais}

Bolsista de Iniciação Científica

Universidade Federal do Rio Grande do Norte

anasmorais@hotmail.com

\section{Mariana Cela}

Bolsista de Iniciação Científica

Universidade Federal do Rio Grande do Norte

E-mail: mariana.cella@bol.com.br

*Endereço para envio de correspondência:

Dr. Martha Traverso-Yépez

154 University Avenue

St. John's, NL, A1B 1Z5 , Canadá

E-mail: mtraverso@mun.ca

Recebido 08/05/2008 Reformulado 02/02/2009 Aprovado 10/02/2009

Campbell, M. L., \& Gregor, F. (2002). Mapping social relations: A primer in doing institucional ethnography. Canadá: Garamond Press.

Crevelim, M. A. (2005). Participação da comunidade na equipe de saúde da família: é possível estabelecer um projeto comum entre trabalhadores e usuários? Ciência \& Saúde Coletiva, 10 (2), 323-331.

Davies, B., \& Harré, R. (1990). Positioning: The discursive production of selves. Journal for the Theory of Social Behaviour, 20(1), 43-63.

Devault, M. L., \& McCoy, L. (2002). Institucional ethnographyusing interviews to investigate ruling relations. In F. J. Gubrium, \& J. A. Holteins (Eds), Handbook of Interview Research (pp. 751-776). Thousand Oaks, CA: Sage.

Franco, T. B., \& Merhy, E. E. (2004). Programa de Saúde da Família (PSF): contradições de um programa destinado à mudança do modelo tecnoassistencial. In E. E. Merhy Jr., H. M. M. J. Rimoli, T. B. Franco, \& W. S. Bueno, O trabalho em saúde - olhando e experienciando o SUS no cotidiano (pp. 55-124). São Paulo: HUCITEC.

Gastaldo, D. (1997). Is health education good for you? Rethinking health education through the concept of bio-power. In A. Petersen \& R. Bunton, (Eds.), Foucault, health and medicine (pp. 113-132). London: Routledge.

Laverack, G. (2005). Public health: Power and professional practice (Paperback). New York: Palgrave Macmillan.

Matumoto, S. (2003). Encontros e desencontros entre trabalhadores e usuários na saúde em transformação: um ensaio cartográfico do acolhimento. Tese De doutorado, Escola de Enfermagem de Ribeirão Preto, Universidade de São Paulo, Ribeirão Preto, SP.

Ministério da Saúde. Secretaria de Gestão do Trabalho e da Educação na Saúde. Departamento de Gestão da Educação na Saúde. (2005). O processo de trabalho em saúde. In Curso de formação de facilitadores de educação permanente em saúde: unidade de aprendizagem - trabalho e relações na produção de cuidado em saúde (pp. 69-79). Rio de Janeiro: Autor/FIOCRUZ.
Parker, I. (1992). Discourse dynamics: Critical analysis for social and individual psychology. London: Routledge.

Parker, I. (1996). Discurso, cultura y poder en la vida cotidiana. In A. J. Gordo López \& J. L. Linaza (Orgs.), Psicologías, discursos y poder (PDP) (pp. 79-92). Madrid: Visor

Peduzzi, M. (2001). Equipe multiprofissional de saúde: conceito e tipologia. Revista de Saúde Pública, 35(1), 103-109.

Smith, D. E. (2005). Institutional ethnography: A sociology for people. Toronto: AltaMira Press.

Spink, M. J. P., \& Medrado, B. (1999). Produção de sentido no cotidiano: uma abordagem teórico-metodológica para análise das práticas discursivas. In M. J. P. Spink (Org.), Práticas discursivas e produção de sentidos no cotidiano: aproximações teóricas e metodológicas (pp. 41-61). São Paulo: Cortez.

Thompson, J. B. (1995). Ideologia e cultura moderna: teoria social crítica na era dos meios de comunicação de massa. Petrópolis, RJ: Vozes.

Traverso-Yépez, M. A., Bernardino, J. M., \& Gomes, L. O. (2007). "Fazem um PSF lá de cima..." Discursos permeando a implementação de uma nova unidade do PSF. Psicologia em Estudo, 12(3), 593-602.

Traverso-Yépez, M. A. (no prelo). The difficulties of dealing with social inequities at the Family Health Program in Natal, Brazil. Critical Public Health.

Vasconcelos, E. M. (1999). Educação popular e a atenção à saúde da família. São Paulo: Hucitec.

Willig, C. (2001). Introducing qualitative research in psychology. Adventures in theory and method. Buckingham: Open University Press. 